\title{
COMPLOT Y PARANOIA EN LA MAESTRA RURAL Y DISTANCIA DE RESCATE
}

\author{
Lucía Feuillet \\ CIECS CONICET Universidad Nacional de Córdoba \\ Ciudad de Córdoba, Argentina \\ lfeuillet@mi.unc.edu.ar
}

RESUMEN / ABSTRACT

\begin{abstract}
Abordamos aquí dos novelas argentinas contemporáneas que cruzan estrategias narrativas paranoicas con figuraciones del complot. La maestra rural (2016), de Luciano Lamberti, narra una conspiración extraterrestre que atraviesa varios regímenes políticos, a partir de una red de voces alucinadas. Distancia de rescate (2015), escrita por Samanta Schweblin, asume la forma de un interrogatorio guiado por un personaje transmigrado que evidencia la amenaza del modelo económico agroexportador. Estas ficciones reestructuran la temporalidad histórica y desnudan las alianzas secretas entre las clases dominantes y el Estado. Nuestra perspectiva hermenéutica sigue la propuesta de Fredric Jameson para interpretar los significados histórico-políticos a partir de dos ideologemas. El complot y la paranoia son estos dispositivos mediadores que nos permiten articular el cruce entre elementos del fantasy, el policial, la ciencia ficción y el terror en el corpus, e integrar estos sentidos a una reescritura de la totalidad fracturada de lo social.
\end{abstract}

Palabras Clave: Lamberti, Schweblin, complot, paranoia, literatura argentina.

\section{PLOT AND PARANOIA IN LA MAESTRA RURAL AND DISTANCIA DE RESCATE}

This article explores paranoid narrative strategies and figurations of the conspiracy in two contemporary Argentine novels. La maestra rural (2017), by Luciano Lamberti, narrates a conspiracy with aliens through various historical periods, a network of hallucinated voices builds this fiction. Distancia de rescate (2015), written by Samanta Schweblin, is a story outlined as an interrogation where a transmigrated character-that shows the consequences of the agro-export business-guides the plot. These fictions restructure historical temporality and show alliances between the ruling classes and the State. Our hermeneutical perspective follows Fredric Jameson's proposal to read the historical-political meanings throughout two ideologemes. In this case, conspiracy and paranoia are the devices that allow us to articulate 
the intersection between fantasy, police genre, science fiction, and horror, and to integrate these meanings into a rewriting of the fractured social totality.

KEYWORDS: Lamberti, Schweblin, conspiration, paranoia, Argentine literature.

Recepción: 14/04/2020

Aprobación: 15/12/2020

\section{COMPLOT, PARANOIA Y HERMENÉUTICA MATERIALISTA}

¿Pueden convivir en un texto literario la subversión de las formas de conocimiento dominantes con el metódico desciframiento de un enigma? En ese caso, ¿qué tipo de lecturas habilitan las obras que combinan matrices discursivas antagónicas (como el policial y el fantasy ${ }^{1}$ )? ¿Y cuáles son los instrumentos teórico-metodológicos adecuados para interpelarlas? Estos interrogantes entrañan problemáticas presentes en el horizonte de este trabajo. Consideraremos aquí el uso de elementos del policial, lo fantástico, la ciencia ficción y el terror en las novelas La maestra rural (2016) de Luciano Lamberti y Distancia de rescate (2014) de Samanta Schweblin², para proyectar un análisis mediado por el complot. En este corpus, la representación de lo sobrenatural o vacilante se opone a las lógicas científicas que sostienen voces narrativas discordantes. De esta manera, se rompe el equilibrio de la racionalidad dominante y se ponen en cuestión los modos en que se organiza lo social.

La propuesta interpretativa delineada por Fredric Jameson orienta nuestra perspectiva teórica. Para este autor, el gesto primordial de la hermenéutica

\footnotetext{
Rosemary Jackson define el fantasy como un "modo" que incluye varios géneros, desde el policial hasta los cuentos de hadas (11). El centro de su estética es la violación de normas y convenciones asociadas a la representación de lo real, de allí su potencial de "subversión" de los supuestos dominantes. En la misma dirección, Pampa Arán destaca que el fantástico contemporáneo impone como premisa la contaminación, la fragmentación y la mezcla, transformándose en un "hipergénero" (21).

2 Los autores seleccionados para este trabajo se inscriben en el marco estético y generacional de la Nueva Narrativa Argentina (Drucaroff), dado que sus obras se desarrollan en el periodo de la postdictadura. Para Drucaroff, lo que caracteriza a estas generaciones de "prisioneros de la torre" es que aún reescriben el trauma de la violencia dictatorial, aunque con rasgos diferenciales que suponen una ruptura con la producción nacional anterior. Los escritores que integran la Nueva Narrativa están doblemente signados, por un lado, por el peso de la militancia o el compromiso político de sus antecesores y, por otro, por la responsabilidad de trazar un rumbo diferente reelaborando la derrota política (34-35).
} 
es el de "historizar" (Documentos 11), que no significa ubicar una obra con relación a determinado "contexto", ni sostener una lectura ajustada a las condiciones de producción. Dicho movimiento cognitivo implica, más bien, dar cuenta de las condiciones de posibilidad de los textos, poniendo en juego la temporalidad como secuencia no lineal franqueada por las contradicciones sociales. En ese sentido debe leerse la siguiente afirmación del crítico norteamericano: "la fuerza de una obra de arte es directamente proporcional a su historicidad" ("La crítica en la Historia" 181).

Así, la hermenéutica dialéctica se define en el cruce entre las teorías marxistas y la interpretación cultural ${ }^{3}$. En Marxismo y forma, Jameson retoma los trabajos de Jean-Paul Sartre, Herbert Marcuse, György Lukács y Ernest Bloch, entre otros, para mostrar cómo se deslinda el sentido social de los objetos culturales partiendo del examen de su "forma" o sus técnicas de concreción. Esto supone considerar la obra de arte como impulso hacia la compresión de una totalidad que incluye lo histórico, más que como un objeto acabado y cerrado en sí mismo (Jameson, Marxismo y forma 275). Para ello, es necesario realizar un recorrido por distintos horizontes de significación ${ }^{4}$ que no apuntan a lo "interdisciplinario", sino a un movimiento que va desde lo especializado (la forma literaria) a lo concreto (los procesos de significación colectivos) (ibid.).

Es decir, la hermenéutica dialéctica configura un modelo de lectura que opera como reescritura del modo de producción en otra clave. Desde esta

\footnotetext{
Según Romero, este modelo interpretativo supone una intención emancipadora: "Se trata de un sentido iluminador de la praxis política del colectivo social oprimido, en tanto que inervador de la acción políticamente transformadora o generador de una comprensión crítica a la sociedad existente" (14).

En su lectura de la interpretación benjaminiana, Jameson postula los siguientes "planos" de significación para una hermenéutica marxista: en el nivel psicológico, Benjamin estructuraría la interpretación de los objetos culturales en torno a las formas del "olvido" o la imposibilidad de asimilar la experiencia presente y su dimensión histórica -en una sociedad sometida a conmociones permanentes el periódico insensibiliza, naturaliza la experiencia de lo novedoso- (Jameson, Marxismo y forma 54-55). Esto exige, en el nivel moral, una reconciliación con el presente, porque la "conciencia" debe superar el nivel destructivo de la individualidad hacia una recuperación colectiva del pasado (Jameson, Marxismo y forma 57). A su vez, el desciframiento del significado social de una obra de arte continúa en el tercer nivel, el alegórico. De allí que en el plano de la historia aparezca la imagen del angelus novus benjaminiano (Benjamin, Escritos políticos 167-181), aquella figura simbólica que mira hacia el pasado desde "un presente del lenguaje en el umbral del futuro" (Jameson, Marxismo y forma 69 ).
} 
perspectiva, el modo de producción no se percibe como una categoría mecanicista que expresa la determinación económica sino una "totalidad conflictiva" que relaciona varios niveles (cultural, ideológico, político, económico) y temporalidades de lo social. A cada una de estas instancias le corresponde una función y eficacia "específica" que depende de la situación histórica, aunque se priorizan sus conexiones. De allí la centralidad de incorporar "mediaciones" que regulen los tránsitos de lo psicológico a lo social, de lo social a lo económico y de lo ideológico a la dimensión conflictiva de la relación entre clases (Jameson, Marxismo y forma 8).

Recurrimos a Theodor Adorno para subrayar el modo en que el concepto de mediación orienta el conocimiento hacia las totalidades "rotas" (no homogéneas ni idénticas a sí mismas) desde las representaciones de lo concreto:

El proceso dialéctico es algo que remite a ambas cosas: a las partes, a los momentos singulares que tenemos que exceder a partir de la fuerza del todo, y al todo, pues el todo, el concepto que tenemos desde siempre y que finalmente ha de ser la verdad, debe modificarse continuamente conforme al patrón de la experiencia de lo singular (Adorno 71-72).

En el caso de la hermenéutica jamesoniana, se define como "ideologema" a la unidad de análisis que opera como mediación desde el lenguaje hacia los sentidos colectivos, que conecta la "experiencia de lo singular" con la ideología de las clases en conflicto, ya sea como parte un sistema conceptual o de creencias, o como potencialidad narrativa (Jameson, Documentos 71). En los textos de nuestro corpus, el complot funciona como un ideologema que impulsa el desciframiento de una serie de contradicciones vehiculizadas no solo por las matrices discursivas en tensión (el policial, el fantasy, la ciencia ficción y el terror), sino también por la convivencia conflictiva entre elementos de distintos modos de producción.

El complot, tal como lo define Luc Boltanski ${ }^{5}$, permite unificar desciframiento y secreto, inteligibilidad y desconocimiento, y de allí que lo retomemos como

En Enigmas y complots. Una investigación sobre las investigaciones, el sociólogo se remonta a los orígenes del espionaje para explicar esta figura conspirativa, asociando dicha forma narrativa que nace en el periodo de entreguerras con la "posibilidad de describir la realidad entera como un vasto complot y, así, acabar la transposición, en el campo de la representación literaria, de lo que se puede considerar la figura dominante en la metafísica 
instrumento de lectura que expone antagonismos imaginarios en conexión con lo real:

\begin{abstract}
Así la realidad, la realidad social, tal como se presenta inicialmente a los ojos de un observador (y de un lector) ingenuo, con su orden, sus jerarquías, sus determinaciones y sus principios de causalidad, se da vuelta y revela su naturaleza de ficción bajo la cual se disimulaba otra realidad, mucho más real, habitada por cosas, actos, actores, planos, nexos, y sobre todo, poderes, de los que nadie hasta entonces sospechaba la existencia y ni siquiera la posibilidad (Boltanski 37).
\end{abstract}

A propósito del clásico de ciencia ficción 1984, Boltanski subraya la relación conflictiva de la imaginación con lo real, evidenciada por el complot. Para el sociólogo, la novela de George Orwell devela los bordes ficcionales de lo existente, que tocan la construcción de la historia -incluyendo las dimensiones temporales del presente, el pasado y el futuro-. Además, 1984 asume la imposibilidad de reconstruir el sentido de una totalidad sugerida en la multiplicidad de sus fragmentos (Boltanski 202). De un modo similar, los textos de Schweblin y Lamberti ponen en juego el carácter conspirativo de lo social y revelan la conflictividad de fuerzas históricas en pugna que caracteriza una totalidad fracturada.

Esta definición requiere a su vez la introducción de otro operador de lectura, que funciona como complemento y contraparte del complot: la paranoia. Dicha noción, presente de forma latente en todo mecanismo de interpretación, contribuye a problematizar la dimensión omnipresente de la sospecha. En la literatura de espionaje se tilda de paranoicos, dice Boltanski, a quienes ocupan el lugar narrativo de descubridores de complots, estén las tramas relacionadas con lo extravagante y lo fantástico -secuestros extraterrestreso con lo realista -la proliferación de sociedades secretas y alianzas entre sectores dominantes- (Boltanski 211). En las novelas de nuestro corpus, el desciframiento exacerbado de signos e indicios que activan algunos personajes problematiza la representación de lo real y la propia práctica interpretativa:

política del siglo XX, pero desde un punto de vista sesgado que pretende superar el conflicto entre interpretaciones divergentes de lo que es objeto del complot, de los actores que intervienen y de las fuerzas que los ligan unos a otros" (191). 
Según Kraepelin, una de las características de las víctimas de esta enfermedad, consiste, precisamente, en prolongar, en las circunstancias ordinarias de la vida, la investigación más allá de lo razonable, como si los contornos y la esencia de la realidad presentaran siempre, a sus ojos, un carácter problemático (Boltanski 38).

Aunque no podemos obviar los rasgos más importantes de este concepto, definidos por Sigmund Freud -los mecanismos de inversión y desplazamiento, los síntomas como alucinaciones, delirio de grandeza y de redención, el contenido del deseo fantaseado que se transforma en persecución, etcétera (Freud 45)-, la paranoia no es abordada en nuestro trabajo desde el punto de vista del psicoanálisis ${ }^{6}$, sino como artefacto interpretativo que da cuenta de las incertezas que tensan los sentidos inteligibles. Para completar la conceptualización de ese eje en el marco de las lecturas sociológicas, Boltanski retoma a Erich Wulff, quien, en "Paranoid Conspiratory Delusion" (1985), amplía el mecanismo de la inversión trabajado por Freud al conjunto de significaciones socialmente construidas y a las relaciones entre los individuos (Boltanski 209). La paranoia representa, entonces, la incertidumbre respecto de lo real y expone la búsqueda de sentidos ocultos que opera de un modo incesante. La cuestión del azar queda así suprimida y las explicaciones de causalidades fragmentarias no proporcionan más que un alivio pasajero (Boltanski 210).

Nuestro movimiento interpretativo exige transformar al complot y la paranoia -que ya se han estudiado en función de la lectura sociológica de géneros "realistas" como el espionaje y el policial en el trabajo de Boltanskien ideologemas capaces de dar cuenta de las contradicciones y antagonismos representados también a partir del fantasy, la ciencia ficción y el terror. De este modo, el gesto de sospecha que se desprende del trabajo narrativo con el complot se transforma con el uso del policial en "delirio interpretativo" (Piglia, "La ficción paranoica" 4), se extiende hasta tocar los bordes de lo real con

\footnotetext{
Según Freud: "El interés del psiquiatra práctico por tales formaciones delirantes suele agotarse, en general, tras establecer él la operación del delirio y apreciar su influjo sobre la dirección que el paciente imprime a su vida [...] El psicoanalista trae, de la noticia que tiene sobre las psiconeurosis, la conjetura de que aun formaciones de pensamiento tan extravagantes, tan apartadas del pensar ordinario de los hombres, se han originado en las emociones más universales y comprensibles de la vida anímica; le gustaría, por eso, conocer los motivos y caminos de esta transformación" (18).
} 
el fantasy, pone en cuestión las propias categorías cognitivas y paradigmas científicos en la literatura de anticipación y revela el funcionamiento de ciertos "poderes ocultos" y nexos sociales insospechables.

\section{LECTORES PARANOICOS Y NARRATIVAS CONSPIRACIONALES}

Como destacamos en el apartado anterior, nuestro corpus exhibe una búsqueda de verdad guiada por los modos retóricos derivados del policial, a partir de la cual todos los comportamientos y enunciados se someten al desciframiento de significados ocultos. Podemos apelar, en este punto, a la idea de Daniel Link sobre el funcionamiento del enigma, elemento que "preserva la ambigüedad de lo racional y de lo irracional, de lo inteligible y lo insondable a partir del juego de signos y de sus significados" (El juego de los cautos 10). El policial, con la ostentación de sus procedimientos interpretativos y su paranoia de sentido, contribuye a desnudar el carácter discursivo, ficcional de la verdad. En el "Prólogo a la tercera edición" de El juego de los cautos, Link afirma:

Sigo pensando que el mundo es una selva de signos [...] sigo pensando que la función del género pasa (y de ahí su interés) por las formas en que intenta resolver la contradicción de lo social [...] sigo pensando que los géneros (entre los cuales brillan sobre los demás el policial, la ciencia ficción y el melodrama) describen mejor que cualquier otro artefacto la historia de la cultura (7).

Podemos plantear entonces la siguiente aserción inicial: la combinación de elementos del policial, la ciencia ficción, el fantasy y del terror modula una pregunta que se dirige hacia la configuración lo real. Ahora, ¿cómo se comportan el complot y la paranoia en este encuentro intergenérico? Ricardo Piglia se constituye en una referencia obligada aquí, debido a su conceptualización de la ficción paranoica. El crítico argentino subrayó la idea del complot como punto de articulación entre los procedimientos de construcción de la ficción y su desciframiento y anticipó la transformación del policial -en combinación con otros géneros de masas- en ficción paranoica ("La ficción paranoica" 4). El complot, para Piglia, refiere a la vez a la figura del lector como censor o conspirador y a la dinámica narrativa del secreto, ya que cualquier ficción implica un armado oculto ("Teoría del complot" 100). En todo caso, este ideologema tematiza y evidencia las contradicciones sociales representadas en los textos, 
define los procedimientos narrativos y propone resoluciones imaginarias, operando en las dimensiones del contenido y los procedimientos literarios.

Si sostenemos, con Piglia, que toda narración puede leerse como un modelo de investigación ("La ficción paranoica" 4), es dable recuperar los tres procedimientos que aluden a la distribución del saber y que delimitan las redes de la intriga en torno a la información que organiza el narrador: el enigma, que se define como un sentido descifrable; el misterio, que apunta más bien a lo incomprensible e inexplicable desde las racionalidades dominantes; y el secreto, que vehiculiza un vacío de saber, o un saber que algunos tienen y otros no (La forma inicial 249). Las distintas matrices discursivas con las que trabajamos pueden leerse en los intersticios de estos procedimientos: en el pasaje del enigma al misterio asoma el tránsito del policial al fantástico, o de la ciencia ficción (que exige una explicación en el marco de los paradigmas científicos) al terror. El secreto, por su parte, codifica la interferencia entre los cuatro géneros.

En este punto, conviene recuperar, a su vez, algunos antecedentes que construyen un posible horizonte de lectura en función de la perspectiva esbozada arriba, poniendo en foco los cruces entre el policial, el terror, el fantasy y la ciencia ficción en la crítica literaria argentina. José Amícola afirma que los géneros literarios suministran un plus de sentido si son considerados territorios donde se disputan significaciones y no moldes fuertemente regulados (11). Así, nuestro interés no es el uso de los géneros literarios en los textos, sino los puntos de contacto y tensión entre sus elementos. En El libro de los géneros recargado, Elvio Gandolfo construye la tradición local de estos géneros considerando fundamentalmente a autores que potenciaron sus efectos proyectando sus combinaciones, como Eduardo L. Holmberg, Leopoldo Lugones, Jorge Luis Borges, Adolfo Bioy Casares y Julio Cortázar entre otros -con la única mención femenina de Angélica Gorodischer- (37-79).

Gandolfo conecta lo fantástico con la ciencia ficción en Argentina a partir de la tensión entre la representación de una "superficie racionalista y cientificista" y otras formas discursivas ligadas al surrealismo y al misticismo (33). El terror queda también definido en una tensión, en este caso, entre la amenaza de lo sobrenatural y la marca de lo siniestro, centrada en factores de "presión fóbica" - como el genocidio de la última dictadura argentina en 1976 
(Gandolfo 299)-. Allí aparece también una referencia a las coordenadas del complot y lo paranoico cuando se habla de "las redes de individualidades de lo social" que "comunican terror" (Gandolfo 376).

En una entrevista recopilada en Escalera al cielo. Utopía y ciencia ficción, Erik Rabkin menciona algunos puntos de contacto entre la ciencia ficción, el policial y lo fantástico, ligados primordialmente al desciframiento: "Es por eso que, a la manera de los acertijos de la literatura policial, toda la ciencia ficción es hasta cierto punto fantástica" (cit. en Link 25). La ciencia ficción supone cierta actitud que imita el método y la lógica científica aunque refiere, a su vez, a saberes o hipótesis alternativas a estos paradigmas. Por eso, la diferencia con el fantasy se sostiene no en los temas que cada género presenta sino en el modo en que estos son tratados (Capanna 20). En todo caso, tanto la literatura de ciencia ficción - en todas sus vertientes - como el terror y el fantasy se vinculan conflictivamente con el discurso positivista que sostiene al policial de enigma y hasta con la perspectiva "sociológica" o de "crítica social" que sostiene al policial negro. Es decir, el cruce de géneros representa de un modo especial los antagonismos discursivos, este objeto así construido solo puede ser abordado por una hermenéutica materialista que tenga en cuenta el cambio histórico y subsuma la validez local de estos sistemas de pensamiento en una totalidad compleja, conflictiva e incompleta (Jameson, Documentos 16).

\section{LITERATURA Y CONSPIRACIÓN EN LA MAESTRA RURAL}

En los últimos años, la narrativa de Luciano Lamberti (Córdoba, 1978)-por ejemplo, el libro de cuentos La casa de los eucaliptus (2017) o la novela La masacre de Kruguer (2019)- se ha concentrado en presentar las dimensiones del extrañamiento en los ámbitos de lo familiar y lo colectivo. La maestra

macabra", que aspira a romper los órdenes de la vida cotidiana segura apuntando a lo secreto. Los puntos de presión fóbica que componen esta danza macabra del horror no responden a miedos sobrenaturales ni individuales (las arañas, las serpientes, las alturas) sino a aspectos sociales, políticos y económicos (Danza macabra).

$8 \quad$ Angela Dellepiane propone algunas tipologías en los relatos de ciencia ficción, entre las que incluye la hard o engineer's $S F$, la science fantasy, la space opera y la speculative $S F$. En todo caso, aquí nos interesa destacar lo que tendrían en común estos tipos discursivos, específicamente, el efecto de extrañamiento cognoscitivo que supone una crítica social de los sistemas de pensamiento vigentes (515-516). 
rural (2016) también invita a desentrañar, en su estructura enigmática, un armado de voces que exhibe la subversión de los contornos de lo real desde las matrices del fantasy y el terror.

La historia gravita sobre el personaje de Santiago, un estudiante que vive en la ciudad de Córdoba, en Argentina, y aspira a formarse como poeta. Su perspectiva paranoica organiza el tránsito del desciframiento en la novela, específicamente el descubrimiento de un complot extraterrestre a través de la lectura. El contrapunto vocal y conspirativo es Angélica Gólik, una escritora "consagrada" aunque perdida en un pueblo del interior, donde trabaja como maestra rural. Jeremías, su misterioso hijo, convoca la figura de la monstruosidad ${ }^{9}$ sobrenatural y el contacto con otros mundos. Tras esta configuración de las relaciones familiares se dibuja la sobreprotección que bordea el incesto como factor de presión fóbica.

El complot y la paranoia son los operadores de sentido que unen las redes de un relato atestado de contrasaberes dóxicos y disputas científicas. Además, la amalgama de voces que rodea el punto de presión fóbica se apoya en el modo discursivo del policial, es decir, hay una investigación subyacente que recoge historias de otros personajes, donde proliferan signos, informaciones fragmentarias e indicios que el lector debe ordenar. Sumado a esto, el acceso a la información narrativa está supeditado a la lógica de una barahúnda vocal delirante. En este sentido, la amenaza de lo extraño puede percibirse tanto en el horizonte enunciativo individual como en el plano colectivo. Por ejemplo, la imagen de una ciudad imperceptiblemente asediada por el peligro aparece en el siguiente fragmento donde Santiago especifica el receloso entorno discursivo de la novela:

Todo normal. Todo muy normal. Casi obscenamente normal. Ahí está el punto. Es una falsa normalidad. Una normalidad aparente. Lo sé porque tuve acceso a ciertas informaciones. Ciertos datos, muy valiosos. Ciertas experiencias de las que tengo que dejar un

\footnotetext{
Teniendo en cuenta la figura del monstruo tal como lo define Michel Foucault en su complejidad jurídico-biológica (61) y moral (80-81), es válido sugerir que casi todos los personajes de las novelas que abordamos se ajustan a algún principio de anormalidad. Si bien este no es el eje de nuestra investigación, podemos señalar que el monstruo representa un desafío a la norma y en ese sentido, cifra dos tipos de verdades en el corpus, una vinculada a la reescritura del policial y a las transgresiones morales o legales y otra vinculada a lo sobrenatural y/o lo fantástico como transgresión de las leyes biológicas.
} 
testimonio antes de que sea tarde (Lamberti 12).

De esta manera, el personaje recrea un tópico frecuente del policial, el del peligro latente en la ciudad por donde vagabundea el paseante -que representa tanto la indagación detectivesca como la potencial criminalidad-(Benjamin, Ilumninaciones II, 49-84). Gilbert K. Chesterton conceptualiza este género como una épica de la modernidad, donde la ciudad es una "nave fantástica" que guarda oscuros secretos (134). En dicho ámbito de ambigüedades e incertezas, el detective recorre los espacios urbanos para "interpretar" cada esquina o cada ladrillo como un símbolo, al modo de un mensaje cifrado o un misterio irresuelto ${ }^{10}$. La actitud de Santiago replica este gesto paranoico en el desplazamiento citadino.

En medio de este despliegue de las sinrazones y hostigamientos que perturban a Santiago se intercala la descripción de la cotidianeidad de Angélica, una perspectiva anclada en el estereotipo de ama de casa apartada de los centros urbanos. No obstante, el personaje trasgrede este estereotipo en dos sentidos: por un lado, a través de la escritura de una poesía tan potente que produce, al menos, extrañamiento -y a la que no accedemos sino por medio de la palabra de sus lectores-; y, por otro, gracias a los repertorios temáticos alternativos que introduce desde el rol de "maestra rural". Así lo atestigua la palabra de Aníbal, su vecino:

El problema es que era maestra. Si hubiera sido ama de casa, almacenera, verdulera, ponele, no habría drama. Pero era maestra $[\ldots]$ Era el modelo de esos chicos. Y estaba loca [...] Puras incoherencias. Eso les enseñaba Angélica. Por ejemplo, había mucha poesía clásica, Gabriela Mistral, Alfonsina Storni, Juana de Ibarbourou. ¿Quién puede tener algo en contra de la poesía? Nadie. El problema era lo

10 Daniel Link contribuye a poner en eje el interés discursivo de los mecanismos paranoicos de construcción de la verdad en el relato policial y en la semiología. La presencia de una verdad discernible indica la posibilidad de un procedimiento que revela los modos de construir lo real: "La literatura policial instaura una paranoia de sentido que caracteriza nuestra época: los comportamientos, los gestos y las posturas del cuerpo, las palabras pronunciadas y las que se callan: todo será analizado, todo adquirirá un valor dentro del campo estructural o de una serie. Se trata de una semiología que, como teoría de la lectura, se aproxima cada vez más a la máquina paranoica de la literatura policial" (El juego de los cautos 13). En este sentido, podemos señalar que el policial funciona como modelo de desciframiento de las cadenas sígnicas que propone la literatura en general. 
otro. La biología, por ejemplo, centrada sobre todo en el estudio de los anélidos, las lombrices, los gusanos. Todo un año viendo eso. La historia: por completo errónea y delirante. Hablaba de conspiraciones, de civilizaciones perdidas, de mensajes ocultos. Había mucho material sobre los comienzos de la civilización, en la época de los sumerios, pero en vez de seguir adelante, Angélica ahí se quedaba, profundizando tanto que los chicos se habían convertido prácticamente en expertos en el tema. La geografía, otro desastre: se hablaba de cadenas montañosas que no existen, de océanos con nombres inexplicables (Lamberti 21-22).

La confirmación, hacia el final de la historia, de que la buena literatura no puede inspirarse en la vida de una "mujer común" (Lamberti 230) funciona como un impulso al encuentro con otros mundos y una alusión a la potencialidad monstruosa de la escritura ${ }^{11}$.

Por tanto, todo el recorrido de la novela toma la apariencia de una serie de preguntas sobre esta dinámica de saberes sociales urdidos en confabulaciones a partir de las intrigas privadas que presentan los personajes. La hazaña paranoica de Santiago se configura como un ida y vuelta desde el presente de huida donde se ubica la enunciación -que referencia, a su vez, la literatura fantástica del siglo XIX como antecedente del propio discurso: "Estoy aterrado, nervioso, a punto de enloquecer, enfermo. A veces, incluso, me pongo a temblar, como en una novela del siglo XIX" (Lamberti 11) ${ }^{12}$ - hacia la revelación del origen extraordinario de la escritura. El testimonio de Santiago representa una estructura laberíntica similar a la del castillo gótico, un camino al saber

11 Para Gabriel Giorgi, la literatura es un medio de expresión de lo singular, que apunta hacia un uso desviado de la lengua (324). Si el monstruo materializa lo invisible, aquello que constituye una potencia desconocida en el umbral de lo anormal de los cuerpos, la literatura es el lugar por excelencia para presentar esta excepcionalidad, porque trabaja con la dislocación de la sintaxis y desborda las clasificaciones sociales ( ibid.)

12 Si hablamos de los relatos del siglo XIX, una referencia ineludible es Howard P. Lovecraft. En El horror sobrenatural en literatura, el autor hace hincapié en la impotencia del psicoanálisis freudiano para explicar la emoción del miedo presente en el terror sobrenatural. Lo que allí impera es la alusión a un modo de conocimiento no racionalizable, que recrea los núcleos de la amenaza: "un extraño destello de fantasía invade algún rincón oscuro de la mente más fría, de tal modo que ninguna racionalización, ni reforma del psicoanálisis freudiano puede anular por completo un escalofrío causado por un bosque solitario o un susurro en el rincón de la chimenea" (14). 
alucinatorio y catastrófico que deviene del tránsito desde el pasado hacia la ruina (Negroni 20-21) y que postula lo impensable como posibilidad.

No obstante, la narración de Lamberti es también una historia delictiva, porque un libro doblemente robado (sustraído y plagiado) motiva la persecución y el acceso al saber del complot. Durante una visita a Angélica, su recientemente descubierta poeta favorita, Santiago le hurta un manuscrito inédito que publica luego como propio. A partir de allí se abre paso al costado delictivo de una persecución con nudos misteriosos y profundos, anclados en la historia. De modo que la crónica de lo extraño en La maestra rural es la historia de una/s trayectoria/s de escritura/s-lectura/s, del plagio como modo de apropiación ilegal de lo leído y, a la vez, del acercamiento a lo monstruoso y lo extraño. Lo que se narra en el encuentro entre lector y autora es un pasaje de la aberración al arte, a la escritura que articula los textos inexplicablemente bellos de Angélica. En ese trayecto, el hallazgo es un saber delirante que provoca rechazo y una potencialidad significante en el vínculo entre lo humano y lo monstruoso. La descripción del choque con ese "otro mundo" en la voz de Santiago muestra el doble efecto de fascinación y horror que esto produce:

Jeremías ya no era él. Lo reconocí por el equipo de gimnasia, hecho un bollo en el piso, porque había abandonado para ese momento su forma humana. Angélica sentada en la cama, desnuda, tenía un tentáculo entrándole por la boca. Eran oscuros, negros y húmedos, los tentáculos. Salían de la cabeza y la espalda de Jeremías, Me recordaron a las anguilas. Unos animales negros, ciegos y asquerosos que vivían en el barro podrido.

Angélica tenía una de esas carpetas grises en las manos, y escribía de un modo mecánico y continuo con un birome azul en ella. Parecía estar abstraída y disfrutar a la vez de lo que pasaba. (Lamberti 244).

Aquí la representación de lo extraño en la figura de Jeremías no personifica solo una apariencia monstruosa, bajo este signo de "anormalidad" se articulan también las dimensiones de otros mundos que coexisten de modo antagónico.

La organización yuxtapuesta de las voces en la novela convoca a descifrar las dinámicas ocultas tras lo real y el significado de un complot que atraviesa espacios y tiempos históricos. A ello se refiere el testimonio de Enrique, un exprofesor de biología que participa en una serie de misiones secretas impulsadas desde el gobierno. Como trabajador del Instituto Nacional de 
Ciencia, a partir de 1947, Enrique recorre el país en busca de anomalías. Su trayecto incluye las provincias de Entre Ríos, el límite de la Pampa, Santiago del Estero, Chaco, frontera con Paraguay, "pero sobre todo la pampa gringa, Córdoba y Santa Fe" (Lamberti 207). El proyecto culmina en el año 1955, estimamos, referencialmente, con el comienzo de la Revolución Libertadora, porque en esa etapa "se desmantela" el Instituto. El personaje evoca todas las dimensiones del conocimiento, que no alcanzan para explicar ni las anormalidades de la "pampa gringa" ni la naturaleza del proyecto estatal:

-Ciencia aplicada. Pero aplicada es un término relativo. No existía un lugar muy preciso donde aplicarla. Había físicos, biólogos, matemáticos, ingenieros, incluso un filósofo idealista. Usted sabe: los que consideran que el mundo material es un producto de la mente. Se nos instaba a ser creativos, a buscar nuevas soluciones para viejos problemas. [...]

-¿Y qué hacían?

-Teníamos ciertas direcciones. Escuchábamos rumores. Buscábamos anomalías. (Lamberti 205-206).

En este punto, la reflexión se transforma en una pregunta sobre la posibilidad de leer señales y el texto comienza a poblarse de personajes que descifran mensajes secretos en la trama de lo cotidiano. El biólogo Bento, por ejemplo, percibe señales en el vuelo de los pájaros y logra modular así el delirio interpretativo: "Si somos convocados, ¿es porque fuimos elegidos realmente o porque tenemos la capacidad de leer la convocatoria?" (Lamberti 233). Hacia el final de la novela, descubrimos que Bento es "B891" y que, a pesar del carácter artificioso y robótico de su designación, no deja de revelar la proporción humano-conspirativa de todo sentido socialmente construido: "La interpretación supone un secreto, algo oculto, algo que debe sacarse a la luz" (ibid.).

Banegas es un empleado de la morgue que descubre regularidades en el vuelo de las moscas, en el curso del río, en el desplazamiento de las mojarritas, etcétera. En base al análisis de estos materiales, el forense averigua el código numérico de un teléfono de línea al que llama para escuchar el mismo mensaje que el resto de los personajes "convocados" - una grabación publicitaria en voz femenina que invita a vacacionar en las Islas Sefarditas-. Con este "método" explicativo, analiza además La aproximación, el libro de poemas de Angélica, concluyendo que existen universos paralelos y convergentes en 
perpetuo movimiento. Joaquín es quien finalmente comprueba las hipótesis del forense y relata su experiencia conflictiva respecto a la apariencia de lo "normal" o el orden "natural" del mundo:

Estoy en el auto, manejando por la ruta, y tengo una conversación en voz alta conmigo mismo. Mi otro yo está sentado al lado mío, en el asiento del acompañante. Parece víctima de una gran preocupación. -Está pasando nomás -dice.

-¿Vos decís? -digo-. ¿Era esto con lo que nos habían amenazado?

- Todos los signos apuntan a eso -dice mi otro yo, muy nervioso, meciéndose hacia adelante y hacia atrás.

-Quizás el otro yo sea yo, y vos seas el verdadero -le digo-. No tengo forma de saberlo. Excepto por el hecho de que si mi yo que maneja es imaginario, ¿cómo maneja?

-Entendiste todo mal -dice mi otro yo.

-Me pasa hace rato -digo.

-Ninguno de nosotros es imaginario -dice mi otro yo (Lamberti 217).

Detrás del mensaje de la empresa de turismo, las investigaciones del Instituto de Nacional de Ciencia, los hallazgos individuales y la literatura de Angélica, se dibuja un complot vigilante que pone en evidencia ciertos vínculos entre lo imaginario y la construcción ficcional de "lo real". La pregunta que subyace no es solo a quién beneficia esta intriga sino también qué tipo de verdades encubre. Todos estos eventos remiten alegóricamente a una red invisible de asociaciones en la superficie social, o más bien, a la trama secreta de poder, siempre inasible, que comprende la compleja y heterogénea alianza entre las clases dominantes y el Estado.

Además, el orden temporal de la novela despliega cronologías no lineales que representan crisis históricas, "momentos de peligro" (Benjamin, Escritos políticos 170) o transformaciones sociales incomprensibles. En estos puntos, la amenaza se redimensiona a partir de la insuficiencia del orden racional para explicar ciertos acontecimientos referenciales como órdenes democráticos que ya no garantizan igualdades o Estados que se vuelven criminales. Por ejemplo, según testifica Enrique, el científico Stoppard (asesor principal del dios sefardí que encabeza la conspiración extraterrestre) tiene un "secretario" llamado López Rega, que lo vigila por la ventana (Lamberti 208). Incluso se menciona varias veces en la novela la colaboración de Juan Domingo Perón con "la causa" de la confabulación alienígena (Lamberti 190). ¿Pueden estos 
vínculos ficcionales inexplicables sugerir de modo alegórico la subrepticia creación alianzas aborrecibles entre el Estado e intereses ajenos, como Triple $\mathrm{A}^{13}$ ?

La Guerra de Malvinas (1982) es otro de los fondos referenciales que "oculta" el reclutamiento de personajes para la maquinación interplanetaria y que encarna un foco social traumático. Este acontecimiento es el pretexto para convocar a Alex, un joven que abandona el núcleo familiar creyendo que va a las islas Malvinas: "El mensaje me sonaba de alguna parte $[\ldots]$ jera una publicidad de los militares! [...] Entonces la señal fue enviada por ellos, pensé. Ellos me pusieron un receptor en la cabeza, por eso puedo oírla" (Lamberti $155)$. En este punto, ¿la guerra es una coartada ficcional para la conspiración? $\mathrm{O}$, más bien, ¿este efecto de superposición de discursos imaginarios podría leerse como alegoría del modo en que el gobierno militar transforma la "guerra sucia" de la tortura en una "guerra limpia" (Monteleone 10-11)? No podemos resolver estas interrogantes, pero sí visibilizar la manera en que las conjuras ficcionales develan una dimensión "real" de las alianzas y las tramas de poder, una simbiosis del Estado con agentes "ajenos", tan externos a los intereses de la población como los extraterrestres de esta novela.

Es decir, los puntos referenciales mencionados marcan crisis sociales y culturales inarticulables, cuyos sentidos solo se atisban a través del dispositivo del complot y la paranoia: "-La capacidad paranoica-dice Riviere-. Leer el pasado como parte de un plan. Tomar elementos históricos fácticos y rearmarlos para que digan algo distinto. Si eso no es creatividad..." (Lamberti 258). La dimensión conspirativa permite problematizar la experiencia del pasado, leer la memoria colectiva herida sin renunciar a la ilusión de totalidad, revelando "complicidades" y redes de poder que de otro modo permanecerían ocultas. Las traumáticas experiencias históricas pueden aprehenderse, así, de manera interrumpida -“a los saltos" (Benjamin, Escritos políticos 178)-y franqueadas por los antagonismos sociales.

13 Desde 1973, la llamada "Alianza anticomunista argentina", conformada por la Policía Federal, Las Fuerzas Armadas y sectores del peronismo, acometió la persecución, tortura y asesinato de sectores considerados "subversivos". José López Rega fue el jefe de este grupo parapolicial que anticipó la criminalización del Estado concretada en 1976 con el gobierno dictatorial culpable del mayor genocidio de la historia nacional. 


\section{PARANOIA Y TRANSMIGRACIÓN EN DISTANCIA DE RESCATE}

La trayectoria literaria de Samanta Schweblin recoge de modo central la representación de lo extraño y lo siniestro (Jackson 65-66) a partir de un uso del lenguaje que expresa más los límites de lo real que sus posibilidades de manifestación. Con libros como Siete casas vacías (2015) o Kentukis (2018), la autora de trascendencia internacional repone los modos en que la intimidad de lo familiar-los núcleos sociales, las actividades cotidianas, las experiencias más comunes desarrolladas en los espacios habituales, etcétera- toca permanentemente los bordes del peligro.

La novela Distancia de rescate (2014) - que en 2021 ha sido llevada al cine como una coproducción chileno-española-norteamericana bajo la dirección de la peruana Claudia Llosa- toma la forma de un interrogatorio testimonial conducido por David, un personaje transmigrado. Al igual que en La maestra rural, un niño-monstruo es quien trama allí la conexión discursiva entre los mundos del misterio inarticulable y el enigma descifrable. En la otra punta del diálogo está Amanda, cuya enunciación evidencia la obsesión permanente por controlar todos los peligros que acechan a su hija Nina, con lo cual se recrea el motivo de la sobreprotección al que aludimos en la novela de Lamberti. El relato toma la forma de un diálogo en flashback con un objetivo preciso, definido por David: identificar el punto exacto del peligro que causa la catástrofe -lugar discursivo donde se emplaza otra vez el ángel benjaminiano-, una irreversible intoxicación de madre e hija.

David guía, pregunta, exige y empuja la ficción, marca sus ritmos, sus pausas, los grados de detallismo en la descripción y, por momentos, se introduce en la conciencia de otros personajes para completar la información que estos ofrecen a medias. Y puede hacerlo porque posee un "saber" experiencial y misterioso que proviene de su contacto con los tóxicos y su supervivencia a un procedimiento terapéutico sobrenatural: la "migración" espiritual. De allí que la novela tome la forma de un alegato paranoico, aunque en un sentido diferente a La maestra rural. Ambos textos parten de una perturbación evidente en el nivel enunciativo que vuelve sospechosa la organización discursiva e incluyen múltiples voces que confieren distintas dimensiones a la información. No obstante, las técnicas narrativas difieren. Si en la novela de Lamberti se despliega un "coro" vocal en el mismo plano, en Distancia de rescate hay una voz (la de Amanda) que contiene 
a las otras ${ }^{14}$, y el juego está concentrado en el modo en que se modifica la fiabilidad enunciativa, conforme el lector accede a distintos horizontes de información.

En la configuración territorial que propone el texto, queda evidenciado que el desarrollo del capitalismo dirige su amenaza hacia las poblaciones rurales gracias al avance del agronegocio ${ }^{15}$. Por lo tanto, aquí es el campo y no la ciudad el escenario del peligro. Al comienzo de la historia, Amanda está vacacionando con Nina en un pueblo que ya no es el inocuo terreno alejado de la contaminación citadina, sino más bien un área de riesgo. Progresivamente, la visión romantizada de la apacible localidad se transforma y los amplios horizontes de un verde tan uniforme como artificial se muestran como zonas de reclusión o panoramas adictivos, de los que no se puede escapar:

Le digo a Nina que tenga cuidado. Me sorprenden las ganas que tengo de tomarme unos mates, las pocas ganas que tengo de subirme al coche y manejar cuatro horas y media hasta la capital. Volver al ruido, a la mugre, al congestionamiento de casi todas las cosas.

¿De verdad este sitio te parece un lugar mejor?

Un grupo de árboles da algo de sombra y nos sentamos en los troncos,

14 Luz Aurora Pimentel destaca que la multiplicación de instancias de la narración implica una multiplicación de las mediaciones y, por lo tanto, una ampliación de las distancias entre los hechos narrados y la lectura. El efecto de este procedimiento es el crecimiento de la incertidumbre narrativa y la desconfianza del lector (28).

15 Según Nicolás Forlani, esta práctica se caracteriza por: "la transectorialidad; la priorización de las necesidades del consumidor global respecto del local; la generalización, ampliación e intensificación del papel del capital en los procesos productivos agrarios; la estandarización de las tecnologías utilizadas, con una intensificación en el uso de insumos de origen industrial, y la generación de tecnologías basadas en la transgénesis que apuntan a reducir las especificidades biológicas y climáticas del agro; y el acaparamiento de tierras para la producción en gran escala, proceso en el que tienen participación central grandes corporaciones financieras y que imprime a las disputas por la tierra el carácter de un fenómeno global" (102). Aunque ya desde los años setenta se impulsa la sojización de Argentina, es a partir de la firma de una resolución que autoriza la producción de soja tolerante al glifosato (1996) que este país se posiciona internacionalmente como productor de la semilla transgénica (Giarraca 119) y, por lo tanto, el modelo agroexportador se impone. Esto implica, en primera instancia, además de la aplicación de un conjunto de tecnologías sobre los productos, la modificación genética de semillas, el empleo de herbicidas y la siembra directa. Entre las consecuencias en la distribución y condiciones de vida de la población podemos mencionar: la pérdida de trabajo de los peones rurales, el desplazamiento de campesinos, el monocultivo y la alteración de la biodiversidad (pérdida de bosques nativos y especies), entre otras. 
cerca del aljibe. Los campos de soja se abren a todos lados. Todo es muy verde, un verde perfumado, y Nina me pregunta si no podemos quedarnos un poco más. Solo un poco (Schweblin 68).

En este fragmento, la intervención de David está marcada por la tipografía cursiva e inserta la sospecha que se transforma en signo de la toxicidad del espacio rural. La dinámica narrativa se ve afectada por el vacío de información que requiere la intervención sistemática del lector ante el juego de indicios en la historia. A su vez, en esta estructura vocal de cajas chinas la desconfianza invade todos los niveles discursivos. El desciframiento paranoico se activa especialmente cuando David marca los detalles "importantes", detiene la narración de Amanda, o la cuestiona. A su vez, Carla, como madre de David y narradora delegada, instala la desconfianza en un gesto que representa el revés de la maternidad sobreprotectora de Amanda. Entre tanto, Amanda sigue siendo la voz principal que no deja de registrar esta problematización:

Te llamó monstruo, y me quedé pensando también en eso. Debe ser muy triste ser lo que sea que sos ahora, y que además tu madre te llame "monstruo".

Estás confundida, y eso no es bueno para esta historia. Soy un chico normal.

Esto no es normal, David. Solo hay oscuridad y me hablás al oído. Ni siquiera sé si realmente esto está sucediendo.

Está sucediendo, Amanda. Estoy arrodillado en el borde de tu cama en uno de los cuadros de la salita de emergencias. Tenemos poco tiempo, y antes de que el tiempo se acabe hay que encontrar el punto exacto (Schweblin 35).

El efecto es el de un testimonio doblemente paranoico, que cuenta un destino inevitable dentro de otro: varias veces se anuncia en el diálogo entre David y Amanda la muerte inminente de esta. Mientras tanto, la declaración de la madre busca el momento crítico de la intoxicación y avanza inevitablemente hacia la catástrofe.

Al mismo tiempo, la historia de Carla nos coloca en el eje de los antagonismos en torno a las producciones económicas regionales, porque la intoxicación de David es consecuencia del monopolio económico del agronegocio en una zona en la que nada que no sea soja puede sobrevivir. La tragedia familiar sobreviene cuando el padre de David impulsa un proyecto económico, la crianza de caballos, pero el padrillo se intoxica bajo el cuidado de Carla, 
al igual que el niño, que queda expuesto a la muerte inminente. Ante esto, la única alternativa posible es la de la transmigración, operación que lo transforma en un monstruo y le otorga, a la vez, una potencia de resistencia: la de encarnar el "pasaje" a la muerte y el contacto con otros mundos -los animales del pueblo que mueren (perros, patos, caballos) son "acompañados" por David, quien sostiene ese tránsito desde el envenenamiento al deceso-.

Ante los signos de enfermedad que presenta David, la medicina tradicional no se configura como una opción en este espacio de ruralidad que tiene acceso limitado a los dispositivos modernos de salud. Los medicamentos no atacan la causa del padecimiento y los médicos tardan horas en llegar a "la salita", que es el lugar de atención local. Por eso las urgencias del pueblo se atienden en la Casa Verde, donde habita una curandera con siete hijos que no prescinden del monopolio agrícola, pues son productores de soja. Allí se opera la "transmigración" de David, que constituye un salvataje del cuerpo y una transgresión a las leyes "naturales". Las manchas rojas en la piel del niño permanecen como huellas de este proceso. No obstante, la transformación más inexplicable es del orden de la conducta, porque el chico comienza a mostrar saberes y comportamientos desconcertantes. Sumado a esto, su voz adquiere protagonismo en la narración de modo proporcional al debilitamiento de la enunciadora principal.

Además, a partir de esta función de guía y mediador entre mundos, David configura un nexo con la comunidad de anormales de la zona, otras víctimas de la organización productiva. Este es el anclaje de un "punto de presión fóbica", donde la niñez colinda con lo incognoscible y el horror. Infantes abúlicos y deformes desfilan por el pueblo en horas impensadas y adolecen de una conducta extraña que los padres y madres no toleran: "No tienen pestañas ni cejas, la piel es colorada, muy colorada, y escamosa también" (Schweblin 108). La presencia de esta dimensión comunitaria del problema activa la exhibición de una sospecha paranoide y, en esta instancia de la novela, se devela la única certeza que la recorre, enunciada por David:

Carla cree que todo es culpa suya, que cambiándome esa tarde de un cuerpo a otro cuerpo ha cambiado algo más. Algo pequeño e invisible, que lo ha arruinado todo.

¿Y es verdad?

Esto no es culpa de ella. Se trata de algo mucho peor (Schweblin 110). 
Aunque parece consciente de su responsabilidad en el ostracismo de David, Carla decide someter a Nina al mismo tratamiento a espaldas de su madre y, mientras, evita el contacto de Amanda con su marido, en un comportamiento que bordea el secuestro.

Así, en la novela de Schweblin el sentido de lo conspirativo es múltiple, se proyecta en los espacios íntimos, abarca los modos de construir los vínculos familiares o amistosos y las transmigraciones ligadas a los proyectos económicos zonales. Sumado a esto, el efecto conspirativo se profundiza en el juego retórico con el desciframiento, que implica cierta información oculta y una búsqueda indicial paranoica, operada en simultaneidad con el momento de riesgo en que es narrada la historia. Guiada por el saber monstruoso que incorpora la dimensión "subversiva" (Jackson 12) y siniestra del fantasy, Amanda solo puede enunciar la verdad en el límite con la muerte. Hacia el final de la novela, David accede definitivamente a la conciencia de Carla para narrar esta visión de maquinación delirante:

Carla está ahora muy cerca. ¿Dónde estás vos? ¿Sabe tu madre que estás conmigo?

Saberlo no la sorprendería, se dice a sí misma que yo estoy detrás de todas estas cosas. Que lo que sea que haya maldecido a este pueblo en los últimos diez años ahora está dentro de mí (Schweblin 111).

Las mujeres y los niños encarnan el punto de presión fóbica donde se proyecta la catástrofe social, un terror originado en la toxicidad del desarrollo económico patriarcal ${ }^{16}$. Pero estos son también quienes pueden testimoniarlo, porque operan mediante dispositivos de enunciación delirantes. Por el contrario, las voces masculinas se ausentan del relato y solo aparecen para confirmar la imposibilidad de articular el desciframiento. Hacia el final, en una efímera exhibición de la perspectiva del padre de Nina, se exhibe con desparpajo esta desidia:

No ve los campos de soja, los riachuelos entretejiendo las tierras secas,

16 Este aspecto cobra vital importancia en un trabajo de Lucía de Leone, publicado en el reciente Tomo $\mathrm{V}$ de la Historia feminista de la literatura argentina. Allí la autora, que aborda (entre otras) la novela de Schweblin, advierte sobre la emergencia de otredades en un espacio rural contaminado y contaminante, donde aparece "una nueva especie: la de esos mismos que no se parecen a sus progenitores porque se parecen entre sí’" (197). 
los kilómetros de campo abierto sin ganado, las villas y las fábricas, llegando a la ciudad [...] No ve lo importante; el hilo finalmente suelto, como una mecha encendida en algún lugar; la plaga inmóvil a punto de irritarse (Schweblin 124).

Pero, ¿qué hay detrás de esta organización invisible del peligro? El recurso a lo inexplicable para aliviar la toxicidad del modelo económico revela que la racionalidad imperante no es eficiente para organizar la producción y la supervivencia de la población. Sin embargo, el cuerpo de David -y el de los otros niños- persiste como testimonio de un conjunto de saberes sobre los focos de riesgo de la existencia social. Este discernimiento puede guiar a los transmigrados hacia un futuro cambiante en el que se proyecta como inevitable la pérdida de ciertas conexiones con lo familiar. De modo que esta ficción conspirativa, que cruza interrogatorios paranoicos con saberes secretos o misterios fantásticos con preguntas latentes sobre el porvenir, parece ser el único modo de puesta en discurso de ausencias y antagonismos en una formación social tan abusiva como atemorizante.

\section{¿PARANOICOSOCOMPLOTADOS? LITERATURAYCONSPIRACIÓN}

Si lo real excede lo constatable, entonces la oscuridad es un don, en tanto conciencia de la opacidad del mundo.

María Negroni, La noche tiene mil ojos

El complot y la paranoia configuran el núcleo de las tramas narrativas de nuestro corpus y el centro de sus procedimientos enunciativos. Estos ideologemas confluyen en un conjunto de contradicciones sociales que se expresan como condiciones de posibilidad de estas novelas, instaladas en el cruce de varios géneros literarios. Las matrices discursivas heredadas del policial, el fantasy y el terror proyectan la incertidumbre hacia una trama anticipativa donde priman el delirio y la duda que corroe toda configuración de lo real. Las estructuras paranoicas orientan el recorrido hacia el saber, en el caso de Amanda en Distancia de rescate, y también de Santiago en La maestra rural.

El enigma que opera al nivel de la historia de Santiago y Angélica apunta al modo en que se produce la literatura, al delito que se descubre al final, el 
plagio que tensiona lectura, apropiación y propiedad en medio de la búsqueda obsesiva de un mensaje trascendental tras la poesía. Desde allí se proyecta una instrucción para leer lo histórico, porque en la novela de Lamberti la criminalidad del Estado -incluso entre dictaduras-, en complicidad con algunos intereses "extraños", constituye el fondo sobre el que pivotea la sospecha conspirativa.

Asimismo, en Distancia de rescate la intoxicación revela una alianza secreta entre quienes llevan adelante la producción zonal y los intereses económicos del agronegocio. Con una proyección hacia lo catastrófico, la trama de la novela de Schweblin exhibe el choque entre el avance del modelo productivo agroexportador y las antiguas configuraciones de la ruralidad como espacio inocuo y seguro. Sin embargo, la amenaza convoca modos de resistencia que operan en el borde de lo cognoscible, la transmigración de los cuerpos representa ese impulso de cambio que no puede explicarse. La infancia es afectada por las huellas de este proceso, el resultado es un porvenir incierto, encarnado por niños deformes y monstruosos, que desafían todas las normas biológicas y morales.

De modo que la migración, en la novela de Schweblin, opera como alegoría o "metáfora epistemológica" -en términos de Alazraki ${ }^{17}$ - de coexistencias conflictivas entre supervivencias del pasado y nuevos modos de construcción social, que no dejan de resignificarse como una amenaza para los más débiles. Del mismo modo, la conspiración extraterrestre, en el relato de Lamberti, juega con la exposición de tramas de poder en las que sobreviven vestigios de crisis inarticulables del pasado, a la vez que se dibujan utopías de paraísos extraterrestres. Las conciencias fragmentarias y paranoicas que narran bosquejan una serie de alianzas entre el Estado y las clases dominantes, cuyos intereses resultan tan ajenos al supuesto bienestar poblacional -asumido como fondo ideológico del capitalismo- como los extraterrestres que figuran la invasión de lo extraño.

17

Jaime Alazraki destaca que el fantástico de Julio Cortázar modera la irrupción de lo otro como una realidad humana enmascarada por la cultura sedimentada: "la realidad es -como decía Johnny Carter en 'El perseguidor'- una esponja, un queso gruyere, una superficie llena de agujeros como un colador y desde cuyos orificios se podía atisbar, como en un fogonazo, otra realidad" (Alazraki 276). En este punto, y asociado al efecto de perplejidad que Alazraki atribuye a la "intención" de los textos neofantásticos, la "metáfora epistemológica" es una noción que problematiza la relación de estos submundos - cuyo sentido o sinrazón puede atisbarse entre los intersticios de los relatos- con el conocimiento. 
Las redes de poder aludidas por el complot-transformado una estructura narrativa potencialmente infinita que convoca los caracteres fantasmáticos de la invisibilidad (Jameson, La totalité comme complot 29)-causan irreparables daños poblacionales y violencias traumáticas, representan fobias sociales aludidas en forma de búsquedas paranoicas. Las ficciones conspirativas que analizamos dan forma a estas contradicciones patentes en las relaciones sociales y exhiben la presencia de una dimensión oculta de la dominación. Vale recuperar aquí la reflexión que realiza Boltanski sobre el desarrollo del espionaje en el siglo XX, donde comienza a problematizarse en el plano ficcional la incerteza que traspasa las relaciones de poder:

Esta incertidumbre sobre la sede del poder se anuda en la intersección entre las ambiciones del Estado por organizar la realidad y los efectos de disgregación de las comunidades tradicionales y de los nexos sociales instituidos, ejercidos por el desarrollo simultáneo del capitalismo. Con ello, afecta la cuestión de las relaciones entre el Estado y la nación o, en otros términos, entre las elites dirigentes y económicas y el pueblo (174).

Finalmente, el modo de producción se reescribe así en clave alegórica como mecanismo de complot parcialmente legible, ya que en la base de estas historias persisten zonas oscuras, que revelan la imposibilidad de componer el sentido de una totalidad social articulada. Sin embargo, cada experiencia, cada "aquí y ahora" narrable proyecta toda la estructura fantasmática del complot (Jameson, La totalité comme complot 31) y los antagonismos que lo atraviesan. La interpretación de estas ficciones a partir del dispositivo de lectura que hemos definido como "hermenéutica dialéctica", exhibe, en todo caso, el modo en que el capitalismo oculta las relaciones de poder que lo sostienen y las vuelve conspirativas. Nuestra lectura hace del complot una herramienta para revelarlas, asumiendo que dicho instrumento "tiene por objeto la construcción de la realidad" (Boltanski 202), pero también la reconfiguración alegórica de las estructuras reales de la dominación.

\section{BIBLIOGRAFÍA}

Adorno, Theodor W. Introducción a la dialéctica. Buenos Aire, Eterna Cadencia, 2013.

Alazraki, Jaime. “¿Qué es lo neofantástico?”. Teorías de lo fantástico. David Roas (ed.), Madrid, Arco Libros, 2001, pp. 265-282. 
Amícola, José. La batalla de los géneros: novela gótica versus novela de educación. Rosario, Beatriz Viterbo, 2003.

ArÁn, PAMPA. "Lo unido y lo enhebrado. Para una teoría del fantástico literario contemporáneo". Fantasmas, sueños y utopías en la literatura, cine y artes plásticas. Cristina Elgue-Martini y Luigi Volta, Córdoba, Ediciones del Copista, 2009.

Benjamin, Walter. Iluminaciones II. Madrid, Taurus, 1972. Escritos políticos. Buenos Aires, Abada Editores, 2012.

BOLTANSKI, Luc. Enigmas y complots. Una investigación sobre las investigaciones. Buenos Aires, Fondo de Cultura Económica, 2016.

Capanna, Pablo. El sentido de la ciencia-ficción. Buenos Aires, Columbia, 1966.

Chesterton, Gilbert Keith. El defensor. Buenos Aires, Interzona, 2018.

De Leone, Lucía. "La pampa errante. Un trayecto de desobediencias." En la intemperie. Poéticas de la fragilidad y la revuelta. Historia feminista de la literatura argentina. Vol. 5. Laura Arnés, Lucía De Leone y María José Punte (eds.), Villa María, Eduvim, 2020, pp. 187-215.

Dellepiane, Ángela B. "Narrativa argentina de ciencia ficción. Tentativas liminares y desarrollo posterior." IX Congreso de la Asociación Internacional de Hispanistas. Francfort, The City University of New York, 1989, pp. 515-525.

Drucaroff, Elsa. Los prisioneros de la torre. Política, relatos y jóvenes en la postdictadura. Buenos Aires, Emecé, 2011.

Feuillet, Lucía. "Los dispositivos del complot en Kentukis, de Samantha Schweblin." Mitologías hoy. Revista de pensamiento, crítica y estudios literarios latinoamericanos 22, 2020, pp. 317-335.

Forlani, Nicolás. "Biopolítica del agronegocio." Insterticios de la política y la cultura. Intervenciones latinoamericanas 4, $\mathrm{N}^{\circ} 8,2015$, pp. 99-114.

Foucault, Michel. Los anormales. Buenos Aires, Fondo de Cultura Económica, 2000.

Freud, Sigmund. "Sobre un caso de paranoia descrito autobiográficametne (Schreber)." Obras completas. Tomo XII. Buenos Aires, Amorrortu, 2017, pp. 11-76.

Gandolfo, Elvio E. El libro de los géneros recargado. Buenos Aires, Blatt \& Ríos, 2017.

Giarraca, Norma y Miguel Teubal. "Disputas por los territorios y recursos naturales: el modelo extractivo", Revista ALASRU Nueva época. Análisis latinoamericano del medio rural 5, 2010, pp. 113-133.

Giorgi, Gabriel. "Políticas del monstruo.” Revista Iberoamericana LXXV, º227, 2009, pp. 323-329.

JACKSOn, Rosemary. Fantasy: literatura y subversión. Buenos Aires, Catálogos, 1986.

JAMESON, Fredric. Documentos de cultura, documentos de barbarie. La narrativa como acto socialmente simbólico. Madrid, Visor, 1989.

La totalité comme complot. Conspiration e paranoia dans l'imaginaire contemporain.

París, Le prairies ordinaires, 2007.

Marxismo y forma. Madrid, Akal, 2016. 
"La crítica en la Historia”. Las ideologías de la teoría. Buenos Aires, Eterna Cadencia, 2014, pp. 161-182.

KInG, Stephen. Danza macabra. Madrid, Valdemar, 2006.

LAMBerti, LuCIANO. La maestra rural. Buenos Aires, Random House, 2016.

Link, DANiEL. El juego de los cautos. Buenos Aires, La marca, 2003.

Escalera al cielo. Utopía y ciencia ficción. Buenos Aires, La Marca, 1994.

Lovecraft, Howard Philip. El horror sobrenatural en la literatura. Buenos Aires, Gárgola, 2019.

Monteleone, JoRge. "Introducción.” Historia crítica de la literatura argentina. Una literatura en aflicción. Noé Jitrik (ed.), Buenos Aires, Emecé, 2018.

Negroni, María. La noche tiene mil ojos. Buenos Aires, Caja Negra, 2015.

Piglia, Ricardo. "La ficción paranoica". Clarín. Suplemento Cultura y Nación, 10 de octubre de 1991, pp. 4-5.

La forma inicial. Buenos Aires, Eterna Cadencia, 2015.

“Teoría del complot." Antología personal, Ciudad de México: Fondo de Cultura Económica, 2014, pp. 99-118.

Pimentel, Luz Aurora. Constelaciones. Ensayos de teoría narrativa y literatura comparada.

Ciudad de México, Universidad Autónoma de México, 2012.

Romero, José Manuel. Hacia una hermenéutica dialéctica. Madrid, Síntesis, 2012.

Schweblin, Samanta. Distancia de rescate. Buenos Aires, Random House, 2014. 